\title{
Cross-stimulus transfer of timing in pigeons
}

\author{
DOUGLAS S. GRANT and TIM C. ROBINSON \\ University of Alberta, Edmonton, Alberta, Canada
}

\begin{abstract}
Pigeons were trained in a delayed matching task in which the samples were short $(2 \mathrm{sec})$ and long $(10 \mathrm{sec})$ presentations of either a houselight or a keylight. Transfer trials involved short and long presentations of the nontrained signal as the sample. In the intermittent transfer test, infrequent transfer trials were intermixed with more frequent training trials; in the sustained transfer test, all trials were transfer trials. The intermittent test revealed only weak transfer. The sustained test revealed transfer in Session 1 only in birds that had received pairings of the transfer signal and food prior to testing. However, regardless of whether the transfer signal had been previously paired with food, birds exposed to consistent contingencies between duration and choice across training and testing learned the transfer task more rapidly than did birds exposed to inconsistent contingencies. It was concluded that some training in which the transfer signal serves as the sample is required before the durations of a transfer signal are related to the rules associating duration and responding.
\end{abstract}

A number of studies have used pigeons and a delayed symbolic matching-to-sample task in which the samples differed in duration (e.g., Grant \& Spetch, 1991; Kraemer, Mazmanian, \& Roberts, 1985; Parker \& Glover, 1987; Spetch, 1987; Spetch \& Wilkie, 1981, 1982, 1983; Wilkie, 1987,1988 ). In the most common version of this task, trials begin with presentation of a signal (e.g., houselight) for either a short (e.g., $2 \mathrm{sec}$ ) or long (e.g., $10 \mathrm{sec}$ ) duration. Following termination of the sample, red and green comparison stimuli are presented for a choice. A response to one comparison is reinforced if the trial began with a short-duration sample; a response to the alternate comparison is reinforced if the trial began with a long-duration sample.

A particularly interesting property of event duration is that it is a feature or characteristic common to all stimuli. This raises the possibility that organisms may abstract, or disassociate, temporal attributes of stimuli from other features of the stimulus. That is, organisms may perceive, and possibly represent, the temporal attribute of a stimulus independently of other attributes of that stimulus. One way in which such abstraction of temporal attributes could be accomplished is specified by the internal clock model of timing (e.g., Church, 1984; Gibbon \& Church, 1984). According to this view, onset of a signal to be timed closes a switch, allowing pulses generated by a pacemaker to accumulate in a counter. Termination of the signal opens the switch, stopping the flow of pulses into the counter. In this view, the temporal properties of a signal correspond to the number of counts (or pulses) in an accumulator. If, as this model suggests, duration is perceived independently of other features of a stimulus, then subjects should dem-

This research was supported by Grant OGP 0443 from the Natural Sciences and Engineering Research Council of Canada awarded to the first author. Reprint requests should be sent to D. S. Grant, Department of Psychology, University of Alberta, Edmonton, AB, Canada T6G 2E9. onstrate cross-stimulus transfer of timing. In the present experiment, we investigated two issues left unresolved by W. A. Roberts, Cheng, and Cohen's (1989, Experiment 1) assessment of cross-stimulus transfer in pigeons (for studies of cross-stimulus timing in rats, see, e.g., Meck \& Church, 1982a, 1982b, and S. Roberts, 1982).

In the W. A. Roberts et al. (1989) experiment, the samples were 2- and 8-sec presentations of houselight in one group, and 2- and 8-sec presentations of a tone in the other group. Following training, a transfer test was administered in which the sample on each trial involved either a 2- or an 8-sec presentation of the nontrained signal. Pigeons trained to time the tone signal demonstrated some, but not complete, transfer during the first session in which the houselight signal replaced the tone signal $(60 \%$ correct for pigeons in which the contingencies between duration and correct comparison were the same as in training, and $35 \%$ correct for pigeons in which the contingencies between duration and correct comparison were the reverse of those in training). On the other hand, no transfer was evident on the first session in which the tone signal replaced the houselight signal in pigeons trained to time the houselight signal $(49 \%$ and $50 \%$ correct in pigeons exposed to reversed or nonreversed contingencies between duration and correct comparison in the transfer phase, respectively). However, transfer effects did emerge beginning on the fifth session of exposure to the tone signal.

W. A. Roberts et al. (1989) interpreted these results as reflecting the relative speed with which pigeons associate an amodal or abstract representation of stimulus duration and the rules for responding. They stated the following:

The tone to light transfer data indicate that pigeons immediately associate light duration with the abstract rules for responding to stimulus duration. When transferred from light to tone, however, pigeons appear to require several days of training before the duration of sound can be related to 
the abstract rules acquired with light. Once this link is made, pigeons begin to show ... transfer. (p. 26)

However, because W. A. Roberts et al. (1989) used a sustained transfer test in which transfer sessions consisted of 48 consecutive trials each involving presentation of the transfer signal, it is possible that performance during the first transfer session in both conditions reflected learning that occurred during the transfer session. One could argue, therefore, that the duration of neither transfer signal was immediately associated with the rules for responding to durations at the onset of transfer testing. In this view, transfer effects were revealed more rapidly in the tone-to-light group than in the light-to-tone group because durations of light were more rapidly associated with the rules for responding (within one session) than were durations of tone (requiring four to five sessions).

To evaluate this possibility, both intermittent and sustained transfer tests were employed in the present experiment. Two groups of pigeons were trained initially on a symbolic matching task in which the samples differed in duration. The samples were short $(2 \mathrm{sec})$ and long $(10 \mathrm{sec})$ presentations of houselight in one group, and short and long presentations of keylight in the other group. During the intermittent transfer test, infrequent trials (12 per session) involving short and long presentations of the transfer signal were interspersed among more frequent trials (48 per session) in which the samples were short and long presentations of the training signal. The contingencies between signal duration and correct comparison stimulus were the same on training and transfer trials. The sustained transfer test, which was conducted following the intermittent transfer test, was similar to the transfer test employed by W, A. Roberts et al. (1989) and involved sessions in which all trials began with short and long presentations of the transfer signal as the sample. The contingencies between signal duration and correct comparison on transfer trials were the same as in training for half of the birds and were the opposite of those in training for the remaining birds.

Positive transfer from the onset of the intermittent test would be anticipated to the extent that (1) the transfer signal was timed from the onset of transfer testing, (2) the duration of both the training and transfer signals was represented amodally, and (3) the durations of the transfer signal were immediately associated with the rules for responding to different durations. On the other hand, a failure of any one of these three conditions to be met would result in little or no transfer during the intermittent test.

The results of the sustained transfer test, assessed in relationship to those of the intermittent transfer test, are relevant to evaluating whether some experience is required before the durations of a transfer signal are associated with rules specifying relationships between durations and responding. For example, finding transfer effects during Session 1 of the sustained transfer test, but not during Session 1 of the intermittent test, would suggest that at least some experience with massed trials is necessary before durations of the transfer signal are associated with the rules for responding.

A second issue of concern in the present experiment was the role of an association between a signal and food in determining whether that signal is timed and/or immediately associated with the rules specifying relationships between duration and correct response. Church (1989, p. 63) suggested that the switch component of the internal clock can be controlled by reinforcement, a suggestion that implies that neutral stimuli are less likely to be timed than are stimuli associated with a significant event such as food (see also Gibbon \& Church, 1984, and S. Roberts, 1982). Moreover, according to Killeen and Fetterman's (1988) behavioral theory of timing, associating a transfer signal and food is a necessary prerequisite to the demonstration of successful cross-stimulus transfer of timing.

In W. A. Roberts et al.'s (1989) experiment, the transfer signal was novel at the onset of transfer testing. This fact leaves open the possibility of interpreting W. A. Roberts et al.'s data in terms of differences in speed of learning to time the transfer signal, rather than in terms of differences in speed of learning to associate durations of the transfer signal and rules for responding. According to this view, pigeons may not have timed either transfer signal at the onset of testing but learned to time the light transfer signal quickly (during Session 1) and learned to time the tone signal slowly (requiring four to five sessions).

In the present experiment, the transfer signal was novel at the onset of transfer testing for half of the birds trained with each signal. For the remaining birds, training sessions included trials designed to establish an association between the transfer signal and food. On these trials, a short or long presentation of the transfer signal was equally likely to terminate in response-independent food or the intertrial interval. By establishing an association between each duration of the transfer signal and food in some birds, we attempted to ensure that the transfer signal would be timed from the onset of transfer testing in at least half of the birds. Hence, a lack of immediate transfer for these animals would imply that there is a role for learning to associate transfer signal duration and response rules in cross-stimulus transfer.

\section{METHOD}

\section{Subjects}

Sixteen experimentally naive Silver King pigeons, obtained from Palmetto Pigeon Plant (Sumter, SC), were maintained in individual cages $(48 \times 42 \times 33 \mathrm{~cm})$ in a colony room with a 12:12-h light:dark cycle. The birds were reduced to $80 \%$ of their free-feeding weight and were maintained at that weight throughout the experiment. Water and grit were continuously available in the home cage.

\section{Apparatus}

Eight identical chambers, the interior dimensions of which were $29 \mathrm{~cm}$ tall, $29 \mathrm{~cm}$ wide, and $24 \mathrm{~cm}$ deep, were employed. Three pecking keys $(2.5 \mathrm{~cm}$ in diameter) were mounted horizontally in a row, spaced $8 \mathrm{~cm}$ apart center to center, $23 \mathrm{~cm}$ above the floor. 
A force of approximately $0.15 \mathrm{~N}$ or greater was required to operate the keys. An Industrial Electronics, Inc. in-line projector was mounted behind each key and was used to project stimuli onto the pecking key. A $5 \times 5.5 \mathrm{~cm}$ opening, the top of which was $10 \mathrm{~cm}$ below the center pecking key, provided access to a food magazine that was illuminated whenever activated. A $28-\mathrm{V}$ houselight, the shield of which was adjusted such that the light emitted was directed toward the ceiling of the chamber, was mounted $4 \mathrm{~cm}$ above the center pecking key. Each test chamber was enclosed in a soundand light-attenuating enclosure. Masking noise was provided by an exhaust fan within the enclosure and by white noise delivered through a speaker in the testing room. The presentation of events within the chambers and the recording of data was accomplished by using a microcomputer located in a separate room.

\section{Procedure}

Training -1 . The birds were trained to eat grain from the magazine and were then autoshaped to peck red and green fields. After each bird began responding reliably to red and green, training on 0 -sec delayed symbolic matching-to-sample began. Each trial began with presentation of a black dot on a white ground on the center key as a preparatory stimulus. The preparatory stimulus was terminated after either a single keypeck or a period of $5 \mathrm{sec}$ withou a response. The preparatory stimulus ensured that pigeons would be oriented toward the center key at the time of signal presentation. Had a preparatory stimulus not been employed, the pigeons transferred from houselight to keylight might have failed to observe all or part of the keylight signal during transfer trials. Termination of the preparatory stimulus was followed immediately by presentation of a short $(2 \mathrm{sec})$ or long $(10 \mathrm{sec})$ signal. For 8 birds, the training signal was illumination of the overhead houselight; for the remaining 8 birds, the training signal was illumination of the center key by a white $X$ on a black ground. Termination of the training signal was followed immediately by presentation of red and green comparison stimuli on the side keys. For half of the birds trained with each signal, a single response to the red comparison stimulus produced reinforcement (3-sec access to grain) on 2-sec sample trials, and a single response to the green comparison stimulus produced reinforcement on 10 -sec sample trials. For the remaining birds, the contingencies were reversed. For all of the pigeons, a single response to the incorrect comparison stimulus produced a 3-sec time-out.

For the 8 pigeons in the no-food group (4 trained with houselight and 4 trained with keylight), the sessions contained 48 trials, and the sample duration was equally often $2 \mathrm{sec}$ and $10 \mathrm{sec}$. Position of the correct comparison stimulus on the right and left keys was balanced within sample duration. The order of the four types of trials (two sample durations $\times$ two positions of the correct comparison stimulus) varied randomly from session to session. A variable intertrial interval (ITI) with a mean of $30 \mathrm{sec}$ separated trials within a session.

For the 8 pigeons in the food group ( 4 trained with houselight and 4 trained with keylight), the sessions were identical to those in the no-food group except that 24 trials were added. On these trials, termination of the preparatory stimulus was followed by a $2-\sec$ ( 12 trials per session) or a $10-\mathrm{sec}$ (12 trials per session) presentation of the transfer signal. Termination of the transfer signal was followed by the ITI on $50 \%$ of the occasions. On the remaining occasions, termination of the transfer signal was followed by response-independent reinforcement (3-sec access to grain) and then the ITI. Within each training session, every third trial involved presentation of the transfer signal.

Intermittent transfer test. Following 28 sessions of training, each bird received three sessions of intermittent transfer testing. Each transfer session consisted of 60 trials, 48 training trials and 12 transfer trials. Transfer trials were identical to training trials except that the transfer signal replaced the training signal-that is, the houselight signal replaced the keylight signal for the birds trained with the keylight, and the keylight signal replaced the houselight signal for the birds trained with the houselight signal. Six transfer trials within each transfer session involved a short $(2 \mathrm{sec})$ presentation of the transfer signal, and 6 trials involved a long $(10 \mathrm{sec})$ presentation of the transfer signal. The contingencies between duration and correct comparison were the same on training and transfer trials. A transfer trial occurred on every 5 th trial within a transfer session. Transfer Sessions 2 and 3 were each preceded by 2 consecutive training sessions identical to those employed during the training phase.

Training-2. Following the final session of the intermittent transfer test, 24 sessions of baseline training, identical to those employed in the first training phase, were conducted. The purpose of this phase was to reduce the effect on performance in the sustained transfer test of any learning that might have occurred during intermittent transfer testing.

Sustained transfer test. During the sustained transfer test, the subjects trained with the houselight were transferred to training with keylight, and the subjects trained with the keylight were transferred to training with houselight. The contingencies between signal duration and correct comparison were the same as those during original training for half of the animals transferred to each signal (consistent subgroups) and were the opposite of those in training for the remaining animals (inconsistent subgroups). Each of the two consistent subgroups (one transferred to houselight and the other to keylight) contained 4 birds. In each consistent subgroup, 2 birds had received trials in which the transfer signal had been followed by food during original training ( 1 bird trained with red positive on short matching trials and green positive on long matching trials, and 1 bird trained with the reverse contingencies), and 2 birds had not experienced the transfer signal during original training (again, 1 bird trained with red positive on short matching trials and green positive on long matching trials, and 1 bird trained with the reverse contingencies). The composition of the two inconsistent subgroups (one transferred to houselight and the other to keylight) was identical to the composition of the consistent subgroups.

Each session contained 48 matching trials, and session details were identical to those experienced by the birds in the no-food group during original training. The subjects transferred to the keylight signal received 30 sessions of training; the subjects transferred to the houselight signal received 20 sessions of training.

\section{RESULTS}

Training -1. The acquisition of matching to duration samples is shown in Figure 1. Although acquisition was more rapid with the houselight signal than with the keylight signal, the asymptotic level of accuracy was unaffected by the type of signal employed. The addition of trials involving presentation of the transfer signal that were sometimes followed by food affected neither the rate nor the asymptotic level of acquisition. A block $\times$ group (food and no food) $\times$ training signal (houselight and keylight) $X$ sample duration (short and long) analysis of variance (ANOVA) revealed significant main effects of block $[F(6,72)=169.41, p<.001]$ and training signal $[F(1,12)=53.72, p<.001]$, and a significant block $\times$ training signal interaction $[F(6,72)=15.01, p<.001]$. No other main effects or interactions were significant.

Intermittent transfer test. Matching accuracy on transfer trials during the intermittent test in each group is shown in Table 1. One-tailed $t$ tests revealed that accuracy ex- 


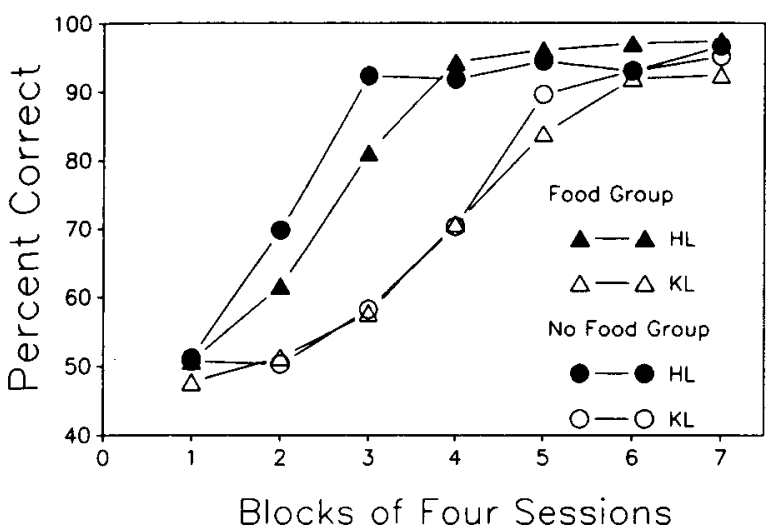

Figure 1. Mean percentage of correct responses as a function of blocks of training sessions on houselight-sample (HL) and keylightsample (KL) trials in the food and no-food group.

Table 1

Mean Percentage of Correct Responses on Transfer Trials During the Intermittent Transfer Test

\begin{tabular}{lccc}
\hline & \multicolumn{3}{c}{ Session } \\
\cline { 2 - 4 } Group & 1 & 2 & 3 \\
\hline Food & 53.2 & $58.3^{*}$ & $61.5^{*}$ \\
No Food & 55.3 & $59.4^{*}$ & 51.1 \\
\hline
\end{tabular}

*Designates means that differ significantly from $50 \%$ at the .05 level, one-tailed.

ceeded chance level in Sessions 2 and 3 in the food group and in Session 2 in the no-food group. A session $\times$ group (food and no food) $\times$ transfer signal (houselight and keylight) $\times$ sample duration (short and long) ANOVA was performed on the data from the transfer trials. The only significant main effect was sample duration $[F(1,12)=$ $8.02, p<.05$ ], revealing higher accuracy on trials initiated by a short sample $(69.8 \%$ correct $)$ than on trials initiated by a long sample ( $43.1 \%$ correct). A significant transfer signal $\times$ sample duration interaction $[F(1,12)=$ $5.37, p<.05$ ] revealed that this effect was more pronounced when the transfer signal was keylight $(80.5 \%$ and $32.0 \%$ correct on short- and long-sample trials, respectively) than when the transfer signal was houselight (59.0\% and $54.2 \%$ correct on short- and long-sample trials, respectively). All other terms in the ANOVA were nonsignificant.

Training -2. Accuracy of each bird exceeded $90 \%$ correct in each of the six blocks of four training sessions.

Sustained transfer test. Matching accuracy during the sustained transfer test is shown in Figure 2. Although learning occurred more rapidly when the transfer signal was houselight than when the transfer signal was keylight, the pattern of the data was not affected by the type of transfer signal. The birds that had not previously been exposed to pairings of the transfer signal and food (open symbols) demonstrated initially little effect of whether the contingencies during transfer were consistent or inconsistent with those during training. Beginning on Session 3, how- ever, accuracy was higher in the birds exposed to consistent contingencies (open circles) than in those exposed to inconsistent contingencies (open triangles). For the birds that had previously been exposed to pairings of the transfer signal and food (filled symbols), accuracy was higher in the birds exposed to consistent contingencies (filled circles) than in those exposed to inconsistent contingencies (filled triangles), beginning in Session 1.

Because different numbers of sessions were conducted as a function of the type of transfer signal, separate session $\times$ contingency (consistent and inconsistent) $\times$ group (food and no food) ANOVAs were performed on the data from the birds transferred to keylight and houselight. The ANOVAs revealed an identical pattern of significant and nonsignificant terms. In the following, the first $F$ ratio and the first $p$ value refer to those obtained in the keylight analysis, and the second $F$ ratio and the second $p$ value refer to those obtained in the houselight analysis.

All three main effects were significant [session, $F(29,116)$ $=60.33$ and $F(19,76)=129.14$, both $p s<.001$; contingency, $F \mathbf{s}(1,4)=54.23$ and $78.94, p \mathrm{~s}<.01$ and .001 ; group, $F \mathrm{~s}(1,4)=19.42$ and $44.47, p \mathrm{~s}<.05$ and .01$]$. The birds that were exposed to consistent contingencies learned more rapidly than the birds that were exposed to
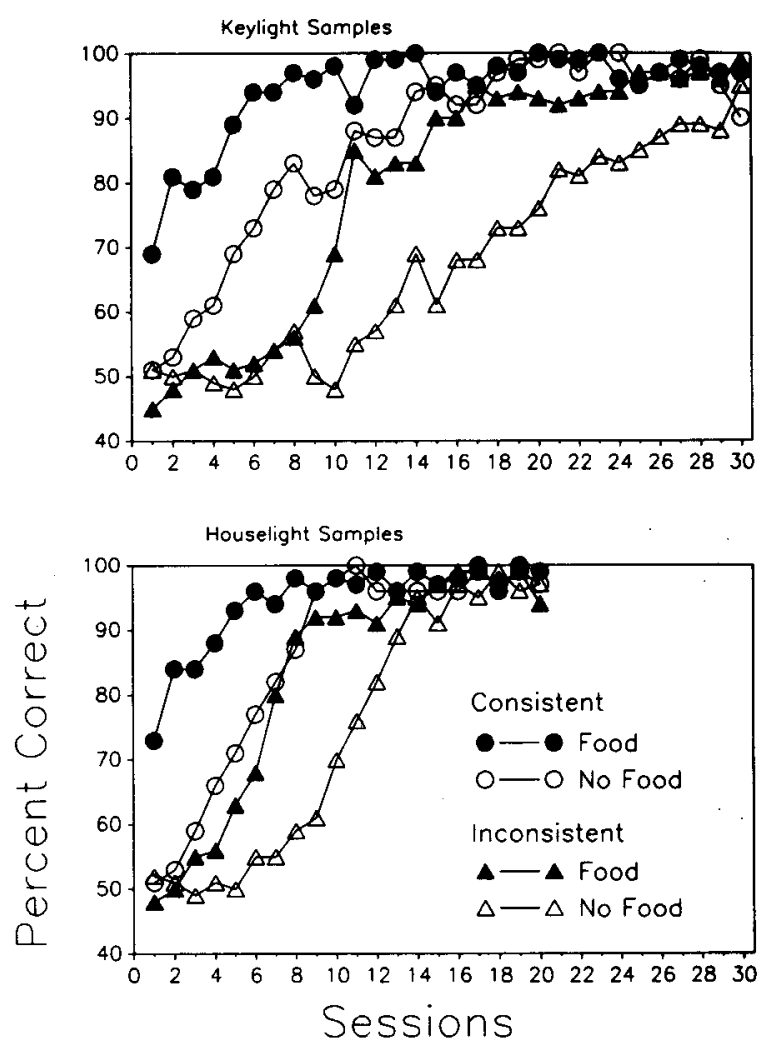

Figure 2. Mean percentage of correct responses as a function of sessions during the sustained transfer test. The top panel shows performance in birds trained with houselight durations and transferred to keylight durations; the bottom panel shows performance in birds trained with keylight durations and transferred to houselight durations. 
inconsistent contingencies [contingency $\times$ session interaction, $F(29,116)=8.62$ and $F(19,76)=13.73$, both $p s<.001]$. Also, the birds that were previously exposed to pairings between the transfer signal and food learned more rapidly than the birds that did not receive those pairings (group $\times$ session interaction, $F(29,116)=1.97$, $p<.01$, and $F(19,76)=7.95, p<.001]$. Finally, the significant contingency $\times$ group $\times$ session interaction $[F(29,116)=5.99$ and $F(19,76)=10.09$, both $p s<$ $.001]$ reflects the finding that in pigeons previously exposed to pairings between the transfer signal and food, accuracy was affected by the type of contingency from the onset of transfer testing, whereas in birds not previously exposed to transfer signal-food pairings, an effect of type of contingency emerged gradually across the first few transfer sessions.

\section{DISCUSSION}

The intermittent test revealed only modest transfer when durations of the transfer signal replaced durations of the training signal as samples. Particularly instructive is the finding that accuracy on transfer trials during Session 1 of the intermittent test did not reliably differ from chance level in either the food or the no-food group. Hence, the results of the intermittent test suggest that transfer that is sometimes obtained in pigeons during the initial session of a sustained transfer test (W. A. Roberts et al.'s, 1989, tone-to-light group and the present food groups) likely reflects not only the influence of learning during the training phase but also the influence of learning during the initial session of transfer testing.

Although little or no cross-stimulus transfer of timing during the intermittent test could reflect a failure to time the transfer signal, we believe that possibility is unlikely, especially for the food groups. These subjects had received extensive pairings of 2- and 10-sec durations of the transfer signal with food, so the passage of time in the presence of this signal was relevant to predicting when food would occur. Consequently, the birds could learn that when this signal was presented, food would occur either after a short or a relatively long period of time. Thus, in our view, the pigeons in the food groups were timing the transfer signal from the onset of testing.

If at least some of the pigeons were timing the transfer signal during the intermittent test, then why was evidence of transfer not obtained? We endorse the suggestion of W. A. Roberts et al. (1989) that pigeons require some amount of training before the duration of a transfer signal is associated with the rules acquired with the training signal. It may be necessary, for example, for pigeons to learn that comparison stimuli are presented on trials initiated by the transfer signal before the duration of that signal is associated with the rules for responding to comparison stimuli. In addition, the present finding that transfer emerged more rapidly in the food groups than in the no-food groups suggests that an association between the transfer signal and food may also be necessary before the duration of the transfer signal is associated with the rules for responding to comparison stimuli.

This latter point provides a plausible explanation of W. A. Roberts et al.'s (1989) finding of greater transfer when the transfer signal was houselight than when it was tone. Specifically, this result may have been caused by a stronger association between houselight and food than between tone and food at the onset of the transfer test. Although neither the houselight nor the tone had been paired with food prior to transfer testing, the birds had extensive experience pecking keylights and receiving food. Because the similarity between houselight and keylights undoubtedly is greater than that between tone and keylights, the association between keylights and food should generalize more strongly to houselight than to tone. If so, and if an association between the transfer signal and food facilitates learning to relate the duration of the transfer signal to the rules for responding, then transfer should emerge more rapidly when the transfer signal is houselight than when it is tone.

Although the results of Kraemer's (1991) recent study of transfer in duration matching appear to question the importance of anticipating comparison stimuli and/or the importance of an association between the transfer signal and food in demonstrating cross-stimulus transfer of timing, transfer may have been precluded by the coding process induced by his training regime. Kraemer trained pigeons on two symbolic matching tasks involving 2-and 10 -sec durations. The problems differed with respect to the signal to be timed (houselight and tone in Experiment 1; white houselight and red keylight in Experiment 2) and the comparison stimuli presented (red and blue for one problem; yellow and green for the other problem). Following training, an intermittent test was administered in which occasional transfer trials were intermixed with standard training trials. On transfer trials, the comparison stimuli were those associated with long and short durations of the alternative signal type. When the signals were houselight and tone, there was no evidence of transfer (48\% correct on intermittent trials); when the signals were houselight and keylight, there was evidence of modest transfer (60\% correct on intermittent trials).

As Kraemer (1991) noted, because a different comparison was correct following each signal of equivalent duration, his training regime may have caused equivalent durations to be coded differently. For example, the four samples may have been coded prospectively as an instruction to respond to a particular comparison stimulus. Moreover, a prospective coding process could also explain Kraemer's finding that accuracy on intermittent trials was higher when the signals were houselight and keylight than when the signals were houselight and tone. Because houselight and keylight are more similar than are houselight and tone, a particular duration of one signal type is more likely to be incorrectly coded as the equivalent duration of the alternative signal type when houselight and keylight, rather than houselight and tone, are used. Because such coding errors would result 
in correct responses on intermittent trials, accuracy on intermittent trials should be higher when the signals are houselight and keylight than when the signals are houselight and tone.

Two other points require consideration. First, in the present experiment, transfer was obtained in Session 1 of the sustained transfer test only in pigeons that had been exposed previously to pairings between the transfer signal and food. In the absence of those pairings, neither pigeons transferred from keylight to houselight nor pigeons transferred from houselight to keylight demonstrated transfer during Sessions 1 and 2. By contrast, W. A. Roberts et al. (1989) found transfer during the first session in pigeons transferred from tone to houselight. Given that the houselight had not been paired with food prior to the transfer test, and given that sessions of transfer testing employed the same number of trials as in our sustained transfer test, we had anticipated some evidence of transfer in the no-food groups during Session 1 of sustained transfer. Although W. A. Roberts et al. used a procedure in which the comparison stimuli were spatially, rather than visually, differentiated, it is unclear how this difference would influence the amount of experience required before the emergence of transfer.

Second, the present experiment revealed that although transfer signal-food pairings had no effect on performance during the intermittent transfer test, they had a dual effect on performance during the sustained transfer test. As noted previously, the first effect of associating the transfer signal and food was to enhance the rate at which transfer effects emerged and, possibly, the strength of those effects. This finding suggests that associating durations of a transfer signal equal in length to the durations to be used as samples may enhance the tendency to associate those durations with rules specifying actions required to obtain food.

A second effect of associating the transfer signal and food was to enhance the rate at which the transfer task was acquired. In the consistent-food groups, the second effect could be a result of the first-that is, enhanced acquisition of the transfer task may have occurred in the consistent-food groups, relative to the consistent-no-food groups, because of the earlier onset (and possibly stronger effect) of positive transfer from the initial training phase. In the inconsistent-food groups, by contrast, any enhancement in transfer effects, in terms of either rate of emergence or strength, would be expected to retard acquisition of the transfer task in the inconsistent-food groups relative to the inconsistent-no-food groups. Thus, the inconsistent groups provide evidence that associating the transfer signal and food enhances rate of acquisition during the transfer phase.

The increased rate of acquisition of the transfer task produced by associating the transfer signal and food might reflect, at least in part, learning of some aspect(s) of the transfer task-for example, that different durations of the transfer signal are relevant to performance. The pigeons previously exposed to pairings between short and long du- rations of the transfer signal and food may have already learned that aspect of the task at the onset of transfer testing.

It should be noted, however, that the associative properties of the transfer signal were confounded with familiarity with the signal (i.e., familiar in the food groups and novel in the no-food groups). Hence, differences in performance during transfer testing between the food and nofood groups may have resulted, in whole or in part, from differences in the signal familiarity. Although the confound could be broken by including groups in which short and long presentations of the transfer signal were followed by no food during training, the food groups were included because two prominent theories anticipate that in the absence of an association between the transfer signal and food, evidence of immediate cross-stimulus transfer of timing would be unlikely (Church, 1989; Killeen \& Fetterman, 1988):

In conclusion, the lack of transfer during the intermittent test in the present experiment is consistent with $\mathbf{W} . \mathbf{A}$. Roberts et al.'s (1989) suggestion that pigeons require some amount of training before the duration of a transfer signal is associated with the rules for test responding acquired with the training signal. Moreover, the present experiment revealed that pairing the transfer signal durations and food prior to transfer testing, a treatment that may have been effective, in whole or in part, because it reduced the novelty of the transfer signal, had two effects on performance. First, the finding that transfer was apparent during Session 1 of the sustained test only in the food groups suggests that prior pairings of the transfer signal and food enhance the rate at which pigeons associate the duration of a transfer signal with rules for test responding acquired with the training signal. Second, the finding that the transfer task was acquired more rapidly in the food groups than in the no-food groups, regardless of whether the transfer task was consistent or inconsistent with the training task, suggests that prior pairings of the transfer signal and food enhance the rate at which pigeons learn a conditional discrimination in which different durations of that signal function as the conditional cues.

\section{REFERENCES}

Church, R. M. (1984). Properties of the internal clock. In J. Gibbon \& L. Allan (Eds.), Annals of the New York Academy of Sciences: Timing and time perception (Vol. 423, pp. 566-582). New York: New York Academy of Sciences.

Church, R. M. (1989). Theories of timing behavior. In S. B. Klein \& R. R. Mowrer (Eds.), Contemporary learning theories: Instrumental conditioning theory and the impact of biological constraints on leaming (pp. 41-71). Hillsdale, NJ: Erlbaum.

Gibbon, J., \& ChURCh, R. M. (1984). Sources of variance in an information processing theory of timing. In H. L. Roitblat, T. G. Bever, \& H. S. Terrace (Eds.), Animal cognition (pp. 456-488). Hillsdale, NJ: Erlbaum.

Grant, D. S., \& Spetch, M. L. (1991). Pigeons' memory for event duration: Differences between choice and successive matching tasks. Learning \& Motivation, 22, 180-199.

Killeen, P. R., \& Fetterman, J. G. (1988). A behavioral theory of timing. Psychological Review, 95, 274-295. 
Kraemer, P. J. (1991). Absence of immediate transfer of training of duration symbolic-matching-to-sample in pigeons. Animal Learning \& Behavior, 19, 276-282.

Kraemer, P. J., Mazmanian, D. S., \& Roberts, W. A. (1985). The choose-short effect in pigeon memory for stimulus duration: Subjective shortening versus coding models. Animal Learning \& Behavior, 13, 349-354.

Meck, W. H., \& ChURCh, R. M. (1982a). Abstraction of temporal attributes. Journal of Experimental Psychology: Animal Behavior Processes, 8, 226-243.

Meck, W. H., \& ChURCH, R. M. (1982b). Discrimination of intertrial intervals in cross-modal transfer of duration. Bulletin of the Psychonomic Society, 19, 234-236.

PARKer, B. K., \& Glover, R. L. (1987). Event duration memory: The effects of delay-interval illumination and instructional cuing. Animal Learning \& Behavior, 15, 241-248.

ROBERTS, S. (1982). Cross-modal use of an internal clock. Journal of Experimental Psychology: Animal Behavior Processes, 8, 2-22.

Roberts, W. A., Cheng, K., \& Cohen, J. S. (1989). Timing light and tone signals in pigeons. Journal of Experimental Psychology: Animal Behavior Processes, 15, 23-35.
SPETCH, M. L. (1987). Systematic errors in pigeons' memory for event duration: Interaction between training and test delay. Animal Leaming \& Behavior, 15, 1-5.

SPETCH, M. L., \& WiLkIE, D. M. (1981). Duration discrimination is better with food access as the signal than with light as the signal. Learning \& Motivation, 12, 40-64.

SPETCH, M. L., \& WILKIE, D. M. (1982). A systematic bias in pigeons' memory for food and light duration. Behaviour Analysis Letters, 2 , 267-274.

SPETCH, M. L., W Wilkie, D. M. (1983). Subjective shortening: A model of pigeons' memory for event duration. Joumal of Experimental Psychology: Animal Behavior Processes, 9, 14-30.

WILKIE, D. M. (1987). Stimulus intensity affects pigeons' timing behavior: Implications for an internal clock model. Animal Learning \& Behavior, 15, 35-39.

WILKIE, D. M. (1988). Proactive effects in pigeons' timing behavior: Implications for an internal-clock model. Animal Leaming \& Behavior, 16, 132-136.

(Manuscript received May 11, 1992; revision accepted for publication August 24, 1992.) 